\title{
Expression of metallothionein 3 in ductal breast cancer
}

\author{
AGNIESZKA GOMULKIEWICZ ${ }^{1}$, KAROLINA JABLONSKA ${ }^{1}$, BARTOSZ PULA ${ }^{1}$, JEDRZEJ GRZEGRZOLKA ${ }^{1}$, \\ SYLWIA BORSKA $^{1}$, MARZENNA PODHORSKA-OKOLOW ${ }^{1}$, ANDRZEJ WOJNAR ${ }^{2}$, JANUSZ RYS $^{3}$, \\ ALEKSANDRA AMBICKA ${ }^{3}$, MACIEJ UGORSKI $^{4}$, MACIEJ ZABEL $^{1,5}$ and PIOTR DZIEGIEL ${ }^{1,6}$ \\ ${ }^{1}$ Department of Histology and Embryology, Wroclaw Medical University, Wroclaw; ${ }^{2}$ Department of Pathomorphology, \\ Lower Silesian Oncology Centre, Wroclaw; ${ }^{3}$ Department of Tumor Pathology, Centre of Oncology, \\ Maria Sklodowska-Curie Memorial Institute, Cracow Branch, Cracow; ${ }^{4}$ Department of Biochemistry, \\ Pharmacology and Toxicology, Wroclaw University of Environmental and Life Sciences, Wroclaw; \\ ${ }^{5}$ Department of Histology and Embryology, Poznan University of Medical Sciences, Poznan; \\ ${ }^{6}$ Department of Physiotherapy, University School of Physical Education, Wroclaw, Poland
}

Received June 13, 2016; Accepted October 3, 2016

DOI: $10.3892 /$ ijo.2016.3759

\begin{abstract}
Metallothionein 3 (MT-3) has the ability to regulate the growth of nerve cells, but the significance of MT-3 expression outside the central nervous system and its participation in carcinogenesis have not yet been clarified. The aim of our study was to investigate the expression of MT-3 in ductal breast cancer and to determine its relationship with well-defined clinicopathological factors in this type of tumor. The study was conducted on 134 cases of invasive ductal breast carcinoma (IDC), 42 samples of non-malignant breast tissue (NMBT), and 26 cases of mastopathy. Moreover, selected breast cancer cell lines (MCF-7, SKBR-3, MDA-MB-231, BO2) and normal human breast epithelial cells (hTERT-HME1) were used. The expression of MT-3 was examined on the protein level using immunohistochemistry and on the mRNA level using real-time PCR. It was shown that the MT-3 protein in cells of IDC and mastopathy appeared in the cytoplasm as well as in the cell nuclei. Both the cytoplasmic and nuclear expression of MT-3 was significantly lower in IDC than in the mastopathies $(\mathrm{p}<0.0001$ and $\mathrm{p}<0.001)$. However, no significant correlation was demonstrated between the level of MT-3 protein and the studied clinicopathological factors. The mRNA expression of MT-3 in IDC was also lower than in non-malignant breast tissue $(p<0.0001)$. Furthermore, in the cases of IDC with lymph node metastasis, the level of MT-3 mRNA was significantly lower than in the cases without metastasis $(p=0.0199)$. The expression of MT-3 mRNA in breast cancer cell lines was significantly lower than in the normal human breast epithelial cell line $(\mathrm{p}<0.001)$. These results suggest that MT-3 may play
\end{abstract}

Correspondence to: Dr Agnieszka Gomulkiewicz, Department of Histology and Embryology, Wroclaw Medical University, Chalubinskiego 6a, 50-368 Wroclaw, Poland

E-mail: agnieszka.gomulkiewicz@umed.wroc.pl

Key words: metallothionein 3, breast cancer a role in the malignant transformation of breast epithelial cells and in tumor progression.

\section{Introduction}

Breast cancer is the most common malignant tumor in women worldwide. Despite considerable progress in diagnosis and therapy, it still constitutes an enormous health problem. In recent years, many studies have sought new predictive and prognostic markers.

Among the factors that have been investigated are the metallothioneins (MTs), intracellular proteins of low molecular weight (6-7 kDa). They are characterized by high levels of cysteine residues and low aromatic amino acid content (1-3). MTs have the ability to reversibly bind heavy metal ions, such as zinc, copper, mercury, lead, and cadmium $(1,4)$. Ten functional metallothionein isoforms have been identified. On the basis of small differences in their amino acid sequences, they are categorized into four groups: MT-1, MT-2, MT-3, and MT-4 (4,5). MT-1 and MT-2 are ubiquitous in all eukaryotic cells. MT-3 and MT-4 were originally described as tissuespecific proteins that occur, respectively, in the neurons of the central nervous system and the squamous epithelium of the skin and gastrointestinal tract. However, recent studies of MT-3 isoform show its broader distribution within an organism (5-10).

The MTs play an important role in maintaining metal ion homeostasis and in protecting cells against heavy metal toxicity and free radicals $(4,11,12)$. Through their interaction with zinc ions, the MTs affect the activity of many zinc-dependent proteins, including enzymes and transcription factors, thus regulating a number of basic intracellular processes, such as proliferation, cell differentiation, and apoptosis (3,12-14). So far, studies have shown an increase of MT-1 and MT-2 in many tumors of both epithelial and mesenchymal origin $(15,16)$. It has been demonstrated that increased expression of MT-1 and MT-2 is associated with greater proliferative potential of tumor cells and is correlated with a more rapid course of the disease and poorer prognosis (17-24). It has also been shown 
that MT-1 and MT-2 are involved in the development of cancer cell resistance to chemotherapy and radiotherapy (25-28).

MT-3 was first identified in neurons of the central nervous system $(6,29)$. It differs from the other MT isoforms by the presence in the molecule of seven additional amino acids, i.e., threonine in the $\mathrm{N}$-terminal region and six amino acids in the C-terminal region (30-32). MT-3 has the ability to inhibit the growth of nerve cells and neurite extension $(6,33)$. In subsequent studies, MT-3 has also been found outside the central nervous system, including the kidney, prostate, and salivary glands (34-38). Furthermore, it has been shown that the expression of this protein is altered in certain cancers, including prostate, bladder, breast, esophageal, stomach, and lung $(36,39-43)$.

The aim of this study was to investigate the expression of MT-3 in ductal breast cancers, as well as to determine the relationship between the expression of MT-3 and well-defined clinical and pathological factors in this type of tumor.

\section{Materials and methods}

Patients and tissue samples. The study was conducted on two separate patient cohorts. In the first group, immunohistochemical (IHC) studies were performed on 134 archival paraffin blocks of invasive ductal breast carcinoma (IDC) and 26 cases of mastopathy obtained from patients treated in the Lower Silesian Oncology Centre in Wroclaw, Poland, from 1999 to 2005. All the tissue specimens utilized for the study were obtained prior to the beginning of treatment. The paraffin sections, stained with hematoxylin and eosin (H\&E), were used to verify the diagnosis and the malignancy grade of the tumors $(\mathrm{G})$, according to WHO criteria (44). The clinical data of patients were obtained from the hospital archives and are summarized in Table I. All patients were treated with mastectomy or conservative quadrantectomy followed by axillary lymph node resection. Adjuvant chemotherapy, appropriate to the stage of the disease, was applied to 112 women $(83.6 \%)$, whereas 88 patients $(65.7 \%)$ were treated with $20 \mathrm{mg}$ tamoxifen daily. Neoadjuvant chemotherapy was administered in patients presenting stage III at diagnosis. Radiotherapy was applied to 63 patients (47.0\%). Patients were aged 57.89 \pm 12.26 years and were followed up for $51.08 \pm 37.61$ months (ranging from 1 to 120 months). During this time 24 patients (17.9\%) died of the disease.

The second patient cohort, the real-time PCR group, comprised 101 IDC patients treated in the Centre of Oncology, Maria Sklodowska-Curie Memorial Institute in Cracow, Poland, during the years 2004-2005. The clinical data of these patients are summarized in Table I. Additionally, in 42 cases non-malignant breast tissue (NMBT) adjacent to the tumor was sampled as a control tissue. Experiments were performed on fresh frozen tumor samples obtained prior to the initiation of systemic treatment, during surgical biopsy, mastectomy, or conservative quadrantectomy followed by axillary lymph node resection. Eighty-five women (84.2\%) were treated with systemic chemotherapy and 57 patients $(56.4 \%)$ received tamoxifen-based therapy. Radiotherapy was applied to 68 patients $(67.3 \%)$. The mean patient age at diagnosis was $56.4 \pm 11.9$ years, and patients were followed up for 58.6 \pm 27.81 months (ranging from 1 to 12 months), during which time 20 patients $(19.8 \%)$ died of the disease. The study protocol was approved by the Bioethical Committee of Wroclaw Medical University.

Cell lines. Four human breast cancer cell lines, MCF-7, SKBR-3 (Cell Lines Collection of the Ludwik Hirszfeld Institute of Immunology and Experimental Therapy, Wroclaw, Poland), MDA-MB-231 (ATCC, Washington, CO, USA), and BO2 (a derivative of MDA-MB-231, provided by Dr Philippe Clezardin, INSERM U664, France), as well as the normal human breast epithelial cell line hTERT-HME1 (ATCC), were used in this study. All the breast cancer cells were cultured in $\alpha$-MEM medium supplemented with $10 \%$ fetal calf serum (FCS; Invitrogen, Carlsbad, CA, USA), 2 mM L-glutamine and antibiotics. The normal human breast epithelial cell line was cultured in MEGM Bullet kit medium (Lonza, Basel, Switzerland).

Immunohistochemistry (IHC). Resected tissue samples were fixed in $4 \%$ buffered formalin, dehydrated and embedded in paraffin. For the IHC reactions, paraffin blocks were cut into $4 \mu \mathrm{m}$-thick sections and fixed on sialinized microscopic slides. Deparaffinization and antigen retrieval were performed using Target Retrieval Solution, pH 9.0 (Dako, Glostrup, Denmark) at $97^{\circ} \mathrm{C}$ for $20 \mathrm{~min}$. Subsequently, the sections were washed in Tris-buffered saline and incubated with primary antibodies at room temperature for $20 \mathrm{~min}$. All immunohistochemical reactions were performed using Autostainer Link 48 (Dako). To detect MT-3 expression, a non-commercial rabbit polyclonal antibody raised against GGEAAEAEAEKC peptide was used (dilution 1:500; Invitrogen). The Ki-67 antigen was detected using mouse monoclonal antibody, clone MIB-1 (prediluted and ready-to-use, code no. IR626; Dako), estrogen receptor (ER) using mouse monoclonal antibody, clone 1D5 (prediluted and ready-to-use, code no. IR654; Dako) and progesterone receptor (PR) using mouse monoclonal antibody, clone 636 (prediluted and ready-to-use, code no. IR068; Dako). The sections were then visualized using EnVison FLEX reagents (Dako). All slides were counterstained with hematoxylin (Dako). HER2 expression status was determined using HercepTest and HER2 FISH pharmDx kit (both from Dako), following the procedure recommended by the manufacturer. All reactions were conducted with negative controls.

Evaluation of IHC reactions. The IHC reactions were assessed under a BX-41 light microscope (Olympus, Tokyo, Japan) in whole-tissue section. The expression of MT-3 in cytoplasm (cMT-3) was evaluated using the semiquantitative IRS scale, according to Remmele and Stegner (45), which was used in our previous study for MT-1/2 assessment in IDC (46). The scale is based on the percentage of tumor cells showing a positive reaction ( 0 points, no cells with positive reaction; 1 point, $1-10 \%$ cells with positive reaction; 2 points, $11-50 \% ; 3$ points, $51-80 \%$; 4 points, $>80 \%$ cells) as well as on the intensity of the reaction color ( 0 points, no reaction; 1 point, low intensity; 2 points, moderate intensity; 3 points, strong intensity reaction color). The final score represents the product of the two values and falls in the range $0-12$. The nuclear expression of MT-3 (nMT-3) and of Ki-67 antigen were evaluated using a semiquantitative five-grade scale based on the proportion of 
Table I. Patient and tumor characteristics.

\begin{tabular}{|c|c|c|c|c|}
\hline \multirow[b]{2}{*}{ Parameters } & \multicolumn{2}{|c|}{ IHC group } & \multicolumn{2}{|c|}{ Real-time PCR group } \\
\hline & No. & $\%$ & No. & $\%$ \\
\hline \multicolumn{5}{|l|}{ Age } \\
\hline$\leq 50$ years & 40 & 29.9 & 30 & 29.7 \\
\hline$>50$ years & 94 & 70.1 & 71 & 70.3 \\
\hline \multicolumn{5}{|c|}{ Menopausal status } \\
\hline Pre & 42 & 31.3 & 29 & 28.7 \\
\hline Post & 92 & 68.7 & 73 & 71.3 \\
\hline \multicolumn{5}{|l|}{ Tumor size } \\
\hline pT1 & 72 & 53.7 & 26 & 25.7 \\
\hline pT2 & 51 & 38.1 & 71 & 70.3 \\
\hline pT3 & 7 & 5.2 & 3 & 3.0 \\
\hline pT4 & 4 & 3.0 & 1 & 1.0 \\
\hline \multicolumn{5}{|c|}{ Lymph nodes } \\
\hline Negative & 71 & 53.0 & 32 & 31.7 \\
\hline Positive & 63 & 47.0 & 69 & 68.3 \\
\hline \multicolumn{5}{|l|}{ pTNM } \\
\hline I & 43 & 32.1 & 10 & 9.9 \\
\hline II & 70 & 52.2 & 54 & 53.5 \\
\hline III & 18 & 13.4 & 37 & 36.6 \\
\hline IV & 3 & 2.3 & 0 & 0.0 \\
\hline \multicolumn{5}{|c|}{ Malignancy grade } \\
\hline G1 & 14 & 10.5 & 2 & 2.0 \\
\hline G2 & 68 & 50.7 & 41 & 40.6 \\
\hline G3 & 52 & 38.8 & 58 & 57.4 \\
\hline \multicolumn{5}{|l|}{ ER } \\
\hline Positive & 105 & 78.4 & 56 & 55.4 \\
\hline Negative & 29 & 21.6 & 45 & 44.6 \\
\hline \multicolumn{5}{|l|}{ PR } \\
\hline Positive & 90 & 67.2 & 50 & 49.5 \\
\hline Negative & 44 & 42.8 & 51 & 50.5 \\
\hline \multicolumn{5}{|l|}{ HER 2} \\
\hline Positive & 23 & 17.2 & 25 & 24.8 \\
\hline Negative & 111 & 82.8 & 76 & 75.2 \\
\hline \multicolumn{5}{|c|}{$\mathrm{ER}^{-} / \mathrm{PR}^{-} / \mathrm{HER} 2^{-}$} \\
\hline Yes & 19 & 14.2 & 23 & 22.8 \\
\hline No & 115 & 85.8 & 78 & 77.2 \\
\hline \multicolumn{5}{|l|}{$\mathrm{Ki}-67$} \\
\hline$\leq 25 \%$ & 85 & 63.4 & NA & NA \\
\hline$>25 \%$ & 49 & 36.6 & NA & NA \\
\hline
\end{tabular}

IHC, immunohistochemistry; ER, estrogen receptor; PR, progesterone receptor; HER2, human epidermal growth factor receptor; NA, not analyzed.

cells with the reaction product: ( 0 points, no reaction; 1 point, $1-10 \%$; 2 points, $11-25 \%$; 3 points, $26-50 \%$; 4 points, $>50 \%$ of cells have the reaction product). The status of ER and PR receptors was scored from 0 to 3 points, depending on the percentage of positive cells ( 0 points, no reactions; 1 point, $1-10 \%$; 2 points, $11-50 \%$; 3 points, $51-100 \%$ stained cells). The expression of HER2 receptors was evaluated using a scale that takes into account both the intensity of the membrane reaction and the percentage of positive tumor cells (47).

RNA isolation, $C D N A$ synthesis and real-time PCR. Total RNA was isolated from the tissue samples and the studied cell lines using RNeasy Mini kit (Qiagen, Hilden, Germany) in line with the manufacturer's protocol. To eliminate genomic DNA contamination, on-column DNase digestion was performed using RNase-Free DNase Set (Qiagen). The quantity and purity of RNA samples were assessed by measuring the absorbance at 260 and $280 \mathrm{~nm}$ with NanoDrop-1000 spectrophotometer (Thermo Fisher Scientific, Wilmington, DE, USA). First-strand cDNA was synthesized using the SuperScript III First-Strand Synthesis System for RT-PCR (Invitrogen). The expression of MT-3 mRNA was determined by real-time PCR with 7900HT Fast Real-Time PCR System and TaqMan Gene Expression Master Mix (Applied Biosystems, Foster City, CA, USA) according to the manufacturer's protocol. $\beta$-actin was used as reference gene. For the reactions, the following sets of primers and TaqMan probes were used: Hs00359394_g1 for MT-3 and Hs99999903_m1 for $\beta$-actin (Applied Biosystems). All reactions were performed in triplicate under the following conditions: activation of polymerase at $50^{\circ} \mathrm{C}$ for $2 \mathrm{~min}$, initial denaturation at $94^{\circ} \mathrm{C}$ for 10 min and 40 cycles of denaturation at $94^{\circ} \mathrm{C}$ for $15 \mathrm{sec}$, followed by annealing and elongation at $60^{\circ} \mathrm{C}$ for $1 \mathrm{~min}$. The relative expression of MT-3 mRNA (RQ) was calculated with the $\Delta \Delta \mathrm{Ct}$ method (48).

Statistical analysis. Statistical analysis was performed using Prism 5.0 software (GraphPad, La Jolla, CA, USA). The Kolmogorov-Smirnov test was applied to test for normality of the distribution. The Mann-Whitney U test was used to compare the expression level of cMT-3 and nMT-3 between the mastopathies and the IDC tissues, as well as the MT-3 RQ between the NMBT and IDC samples. For paired sample analysis, the Wilcoxon matched pairs test was used. The Kruskal-Wallis and Dunn's Multiple Comparison tests were utilized to analyze data from more than two groups. The correlations between the clinicopathological parameters and MT-3 expression were analyzed using the Mann-Whitney $\mathrm{U}$ test, Fisher's exact test and Spearman's correlation test. The Kaplan-Meier method and the log-rank test were used to analyze patients' overall survival. For each variable, the hazard ratio (HR) and the $95 \%$ confidence interval $(95 \% \mathrm{CI})$ were estimated. The Unpaired t-test was used to compare differences of MT-3 mRNA expression in studied cell lines. The results were considered statistically significant in the analyses when $\mathrm{p}<0.05$.

\section{Results}

Immunohistochemical MT-3 expression and its impact on the patient clinicopathological data. We noted nuclear as well as cytoplasmic MT-3 expression in the duct cells of mastopathies and in cancer cells of IDC (Fig. 1). Significantly higher nMT-3 and cMT-3 expression was found in mastopathies than in IDC cancer cells $(\mathrm{p}<0.0001$ and $\mathrm{p}<0.001$, respectively; 
A

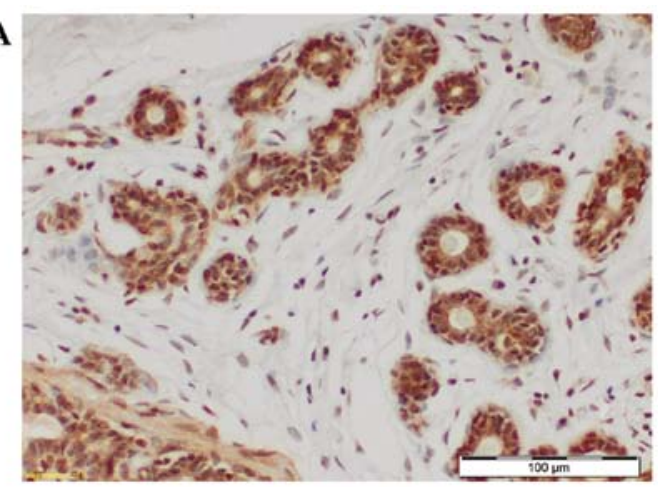

C

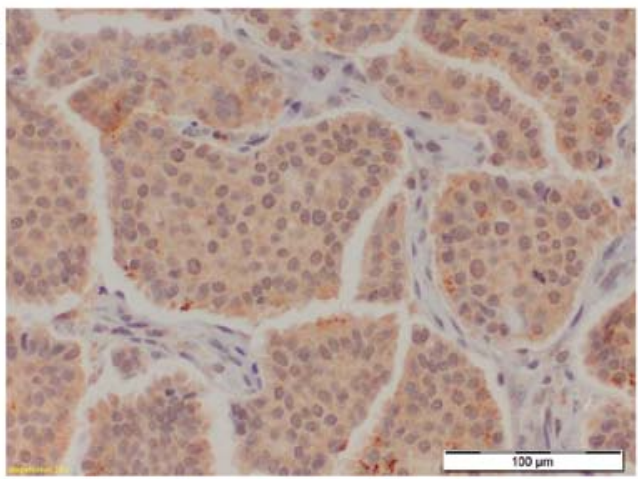

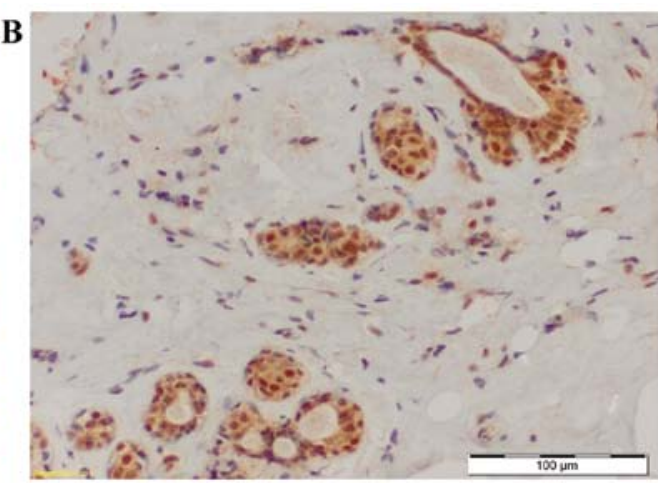

D

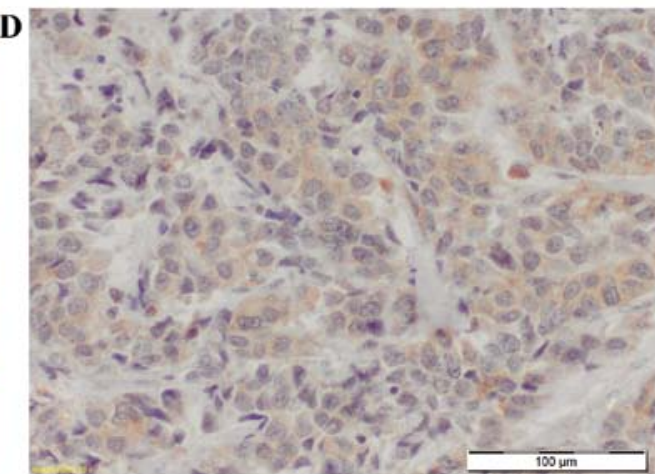

Figure 1. Immunohistochemical expression of metallothionein 3 (MT-3) in cytoplasm and nuclei in duct cells of mastopathies (A and B) and in invasive ductal breast cancer (IDC) cells (C and D). Magnification, x200.

A

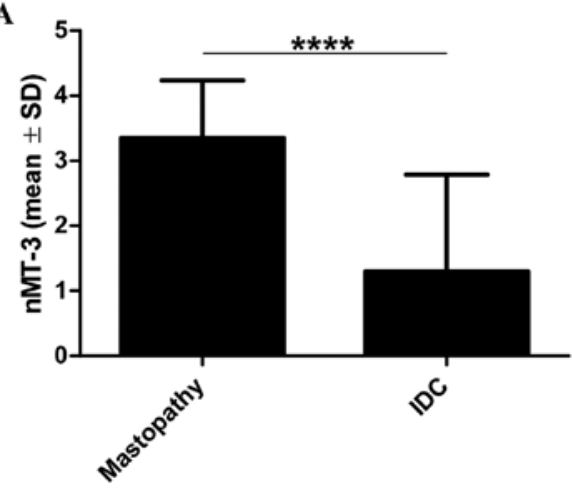

C

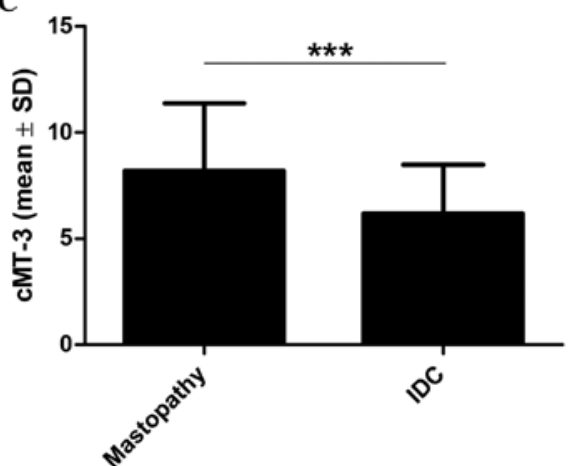

B

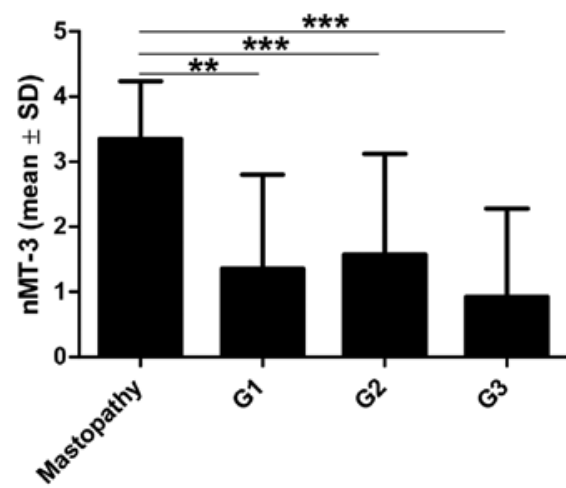

D

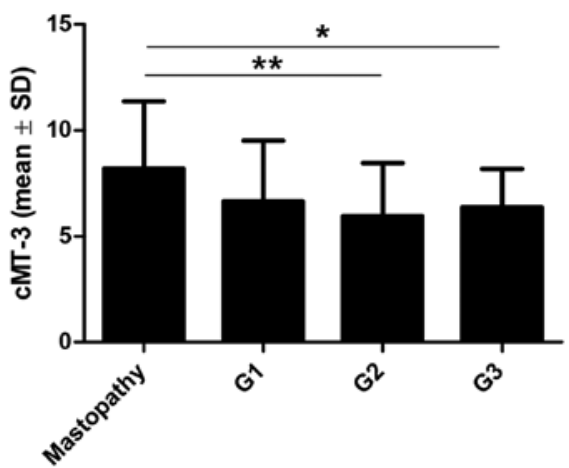

Figure 2. Nuclear (nMT-3; A and B) and cytoplasmic (cMT-3; C and D) metallothionein 3 expression in mastopathies in relation to all the analyzed cases of IDC (A and C; Mann-Whitney test) and IDC presenting particular malignancy grades (B and D; Dunn's Multiple Comparison test). Data presented as mean \pm standard deviation (SD). ${ }^{*} \mathrm{p}<0.05 ;{ }^{* *} \mathrm{p}<0.01 ;{ }^{* * *} \mathrm{p}<0.001 ;{ }^{* * * *} \mathrm{p}<0.0001$.

Fig. 2). When nMT-3 and cMT-3 expression intensities were compared in IDC cases of particular malignancy grades, no significant differences were found (Fig. 2). Statistical analysis revealed that nMT-3 expression was significantly higher in 

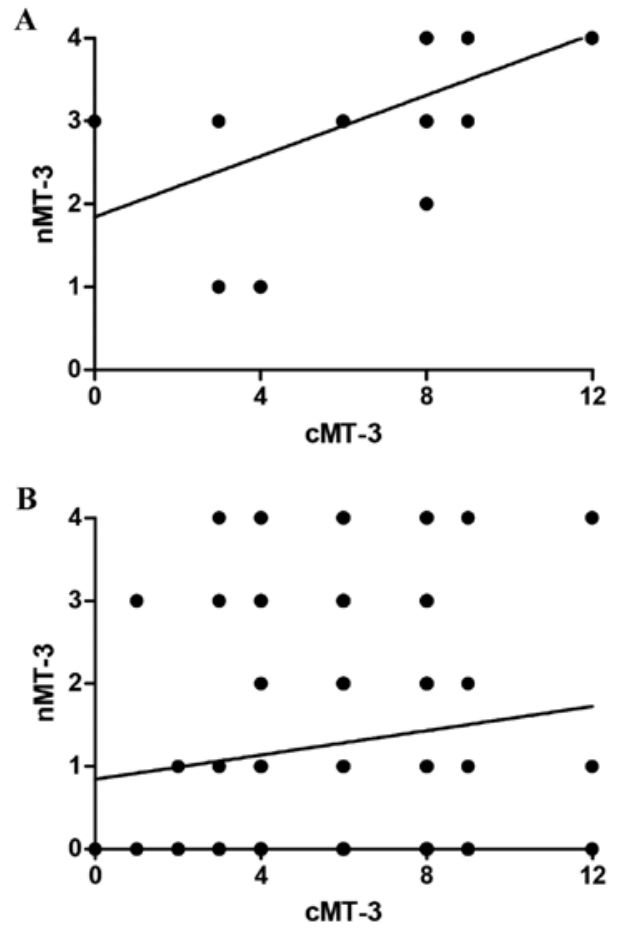

Figure 3. Significant positive correlation of nuclear (nMT-3) and cytoplasmic (cMT-3) metallothionein 3 expression in the mastopathy cases (A; $r=0.71$, $\mathrm{p}<0.0001)$. No significant association was noted in IDC (B).

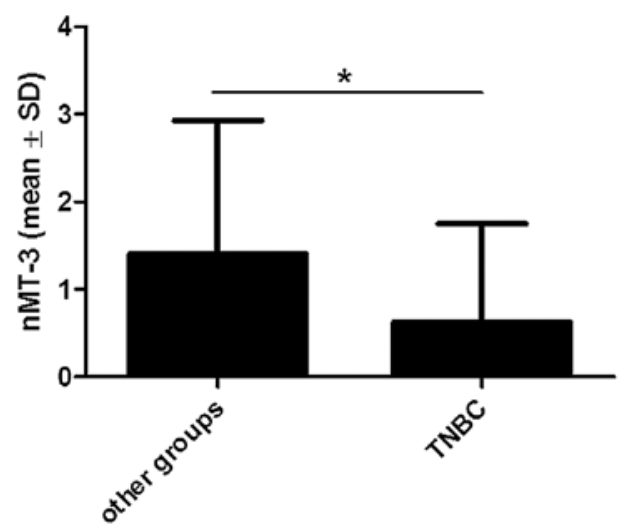

Figure 4. Nuclear expression of metallothionein 3 (nMT-3) in triple-negative (TNBC) and non-triple-negative (other groups) breast cancer cases. Data presented as mean \pm standard deviation (SD). ${ }^{*}$ p $<0.05$.

mastopathies $(3.35 \pm 0.89)$ than in $\mathrm{G} 1(1.36 \pm 1.45 ; \mathrm{p}<0.01)$, G2 $(1.57 \pm 1.55 ; \mathrm{p}<0.001)$ and G3 $(0.92 \pm 1.36 ; \mathrm{p}<0.001)$ cases Similar relationships were noted for cMT-3 expression, which was significantly higher in mastopathies (IRS 8.19 \pm 3.18 ) than in G2 (IRS 5.96 $\pm 2.50 ; \mathrm{p}<0.01$ ) and G3 (IRS 6.37 \pm 1.81 ; $\mathrm{p}<0.05)$. nMT-3 expression was also significantly higher in G2 than in G3 cases ( $\mathrm{p}=0.017)$. Interestingly, the nMT-3 and cMT-3 expression correlated in the analyzed mastopathy cases ( $r=0.71, p<0.0001$ ), but not in the IDC tissues (Fig. 3). Moreover, it was found that nMT-3 expression was significantly lower in triple-negative breast cancers (TNBC: ER', $\mathrm{PR}^{-}$and HER2-) than in the other IDC cases ( $p<0.05$; Fig. 4).

For statistical analysis, nMT-3 and cMT-3 expression was categorized, in order to enable comparison with the
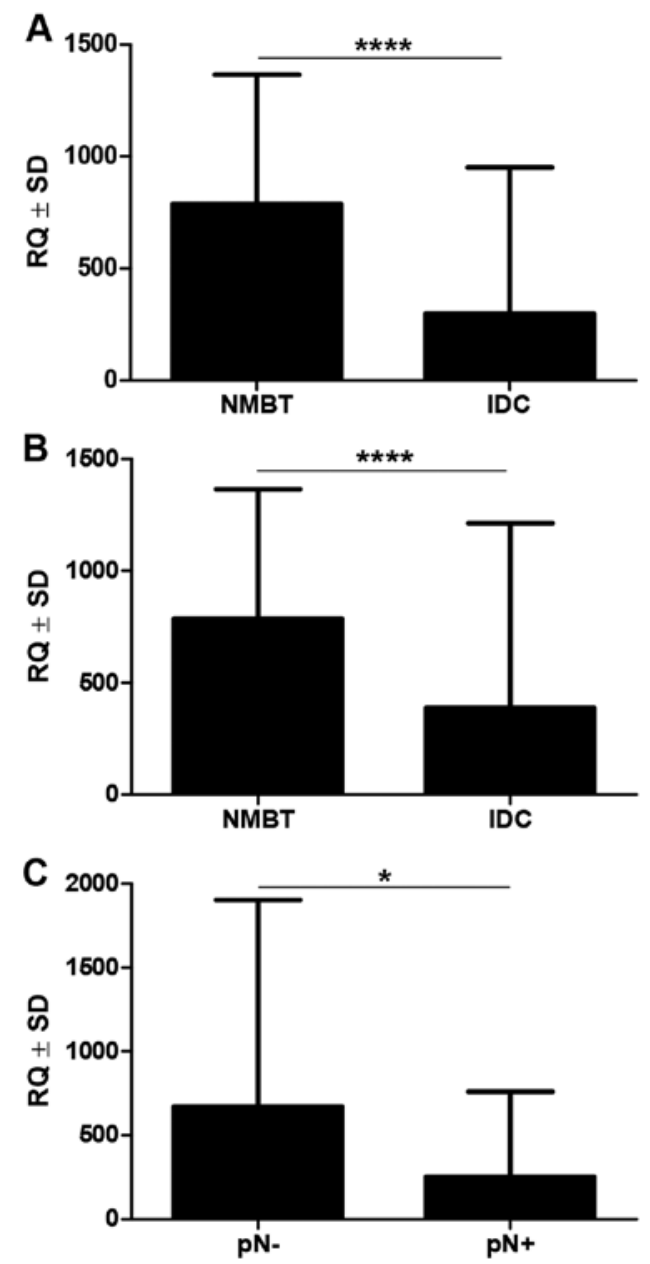

Figure 5. Metallothionein 3 (MT-3) mRNA expression in paired (A) and all (B) non-malignant breast tissue (NMBT) and in invasive ductal breast cancer (IDC). MT-3 RQ in regard to the presence of lymph node metastases (C). Analysis with the use of Wilcoxon matched pairs test (A) and Mann-Whitney test (B and C). Data are presented as mean \pm standard deviation (SD) of the relative expression level (RQ). ${ }^{*} \mathrm{p}<0.05 ;{ }^{* * * * *} \mathrm{p}<0.0001$.

clinicopathological data of the patient. Cases which showed nMT-3 expression level in cancer cells $\leq 10 \%$ were regarded as 'low', while those showing nMT-3 expression $>10 \%$ were regarded as 'high'. In cMT-3, cases with an IRS of 0-6 were classified as 'low', and those with an IRS of 8-12 as 'high'. Statistical analysis using Fisher's exact test did not reveal any significant associations in either nMT-3 or cMT-3, with the clinicopathological data of the patients, such as age at diagnosis, menopausal status, primary tumor size, the presence of lymph node metastases, pTNM stage, malignancy grade or expressions of ER, PR or HER2. nMT-3 and cMT-3 had no impact on cancer cell proliferation measured by the expression of the Ki-67 antigen in cancer cells (data not shown).

MT-3 mRNA expression level in NMBT and IDC samples. Real-time PCR revealed that MT-3 mRNA expression was significantly upregulated in NMBT tissues (mean 786.5 \pm 579.3 ), as compared to the paired (mean 296.8 $\pm 653.6, \mathrm{p}<0.0001$, Wilcoxon matched pair signed rank test) and all (mean 386.8 \pm 826.3 , p<0.0001, Mann-Whitney U test) analyzed IDC cases (Fig. 5). Cases characterized by lymph node involvement 

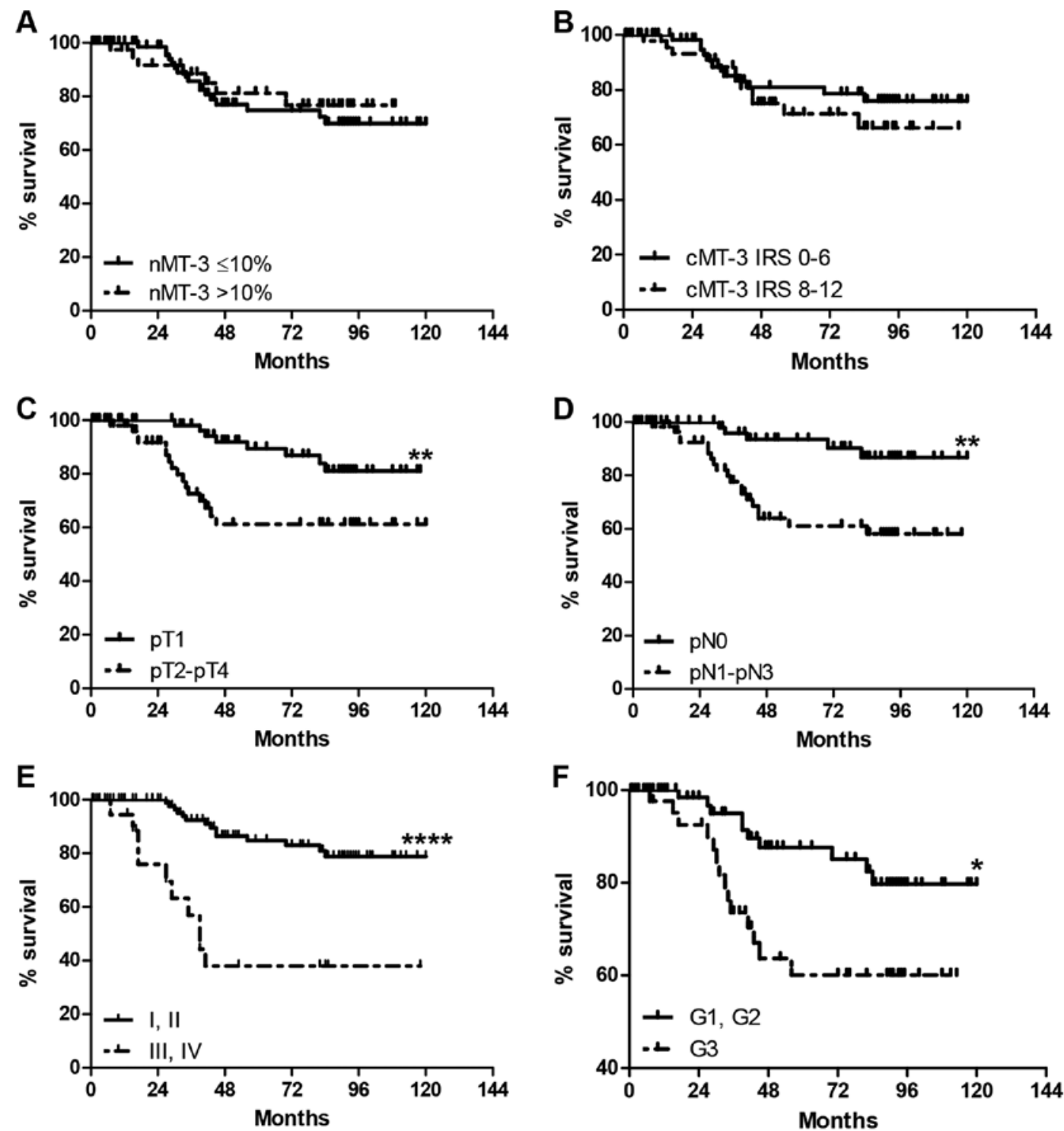

Figure 6. Kaplan-Meier survival curves in regard to nuclear (nMT-3) (A) and cytoplasmic (cMT-3) (B) metallothionein 3 expression, primary tumor size (C), presence of lymph node metastases (D), pTNM stage (E) and malignancy grade (F). Analysis using Mantel-Cox test. ${ }^{*} \mathrm{p}<0.05 ;{ }^{* *} \mathrm{p}<0.01 ;{ }^{* * * *} \mathrm{p}<0.0001$.

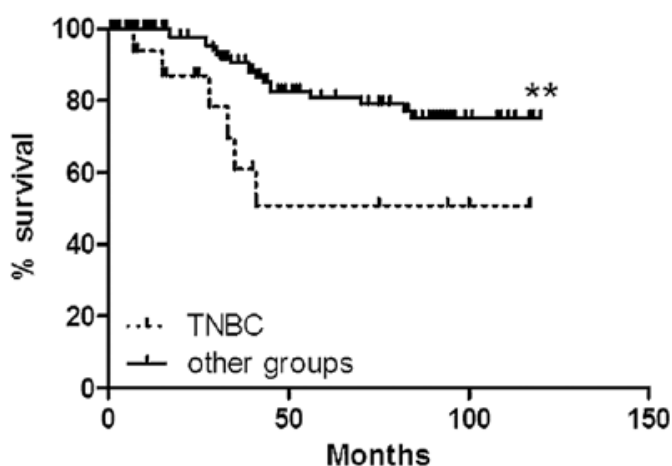

Figure 7. Kaplan-Meier overall survival curves of triple-negative (TNBC) and non-triple-negative (other groups) breast cancer cases. Analysis using Mantel-Cox test. ${ }^{* * *} \mathrm{p}<0.01$.

had significantly lower MT-3 RQ levels than cases without lymph node involvement $(254.0 \pm 506.2$ vs. 673.1 \pm 1232 , $\mathrm{p}=0.0199$; Fig. 5). No associations were noted between the expression level of MT-3 mRNA and patient age, menopausal status, primary tumor size, malignancy grade, Ki-67 antigen expression or status of ER, PR or HER2 (Mann-Whitney U test, data not shown).

Prognostic significance of MT-3 expression. Univariate survival analysis performed in all studied IDC cases $(n=134)$ revealed that the intensity of nMT-3 and cMT-3 expression had no impact on the overall survival (OS) of the patients. Of the factors investigated here, larger primary tumor size $(\mathrm{p}=0.0038)$, presence of lymph node metastases $(p=0.0011)$, advanced disease stage $(\mathrm{p}<0.0001)$ and G3 malignancy grade $(\mathrm{p}=0.0124)$ were associated with the patient poor OS (Table II and Fig. 6).

In addition, we examined impact of nMT-3 and cMT-3 expression on the patient overall survival in triple-negative (TNBC; $n=19$ ) and non-triple-negative (other groups; $n=115$ ) IDC samples. TNBC cases were characterized by a significantly shorter overall survival of the patients as compared to the other groups $(\mathrm{p}<0.01$; Fig. 7). In analyzed TNBC group, 
Table II. Univariate analysis of overall survival in invasive ductal breast carcinoma patients in the immunohistochemical and real-time PCR groups. Significant p-values are given in bold.

\begin{tabular}{|c|c|c|c|c|c|c|}
\hline \multirow[b]{2}{*}{ Clinicopathological factor } & \multicolumn{3}{|c|}{ Immunohistochemical group } & \multicolumn{3}{|c|}{ Real-time PCR group } \\
\hline & HR & $95 \% \mathrm{CI}$ & p-value & HR & $95 \%$ CI & p-value \\
\hline nMT-3 (low vs. high) & 1.231 & $0.5271-2.876$ & 0.6309 & - & - & - \\
\hline cMT-3 (low vs. high) & 0.6957 & $0.3071-1.576$ & 0.3845 & - & - & - \\
\hline MT-3 RQ (low vs. high) & - & - & - & 0.8775 & $0.3528-2.182$ & 0.7787 \\
\hline Age ( $\leq 50$ vs. $>50$ years) & 1.692 & $0.7372-3.885$ & 0.2146 & 0.7633 & $0.2882-2.022$ & 0.5868 \\
\hline Menopausal status (pre vs. post) & 1.299 & $0.5711-2.953$ & 0.5330 & 1.003 & $0.3802-2.648$ & 0.9946 \\
\hline Tumor size (pT1 vs. pT2-pT4) & 3.399 & $1.483-7.789$ & 0.0038 & 1.163 & $0.4324-3.128$ & 0.7649 \\
\hline Lymph nodes (pN0 vs. pN1-pN3) & 3.822 & $1.708-8.554$ & 0.0011 & 1.158 & $0.4292-3.125$ & 0.7720 \\
\hline Stage (I, II vs. III, IV) & 19.28 & $5.497-67.66$ & $>0.0001$ & 1.460 & $0.5629-3.787$ & 0.4364 \\
\hline Malignancy grade (G1, G2 vs. G3) & 2.948 & $1.264-6.878$ & 0.0124 & 1.037 & $0.4207-2.557$ & 0.9367 \\
\hline Ki-67 expression ( $\leq 25$ vs. $>25 \%$ ) & 2.263 & $0.9319-5.495$ & 0.0712 & - & - & - \\
\hline
\end{tabular}

PCR, polymerase chain reaction; HR, hazard ratio; CI, confidence interval; nMT-3, nuclear metallothionein 3; cMT-3, cytoplasmic metallothionein 3; RQ, mRNA relative expression.
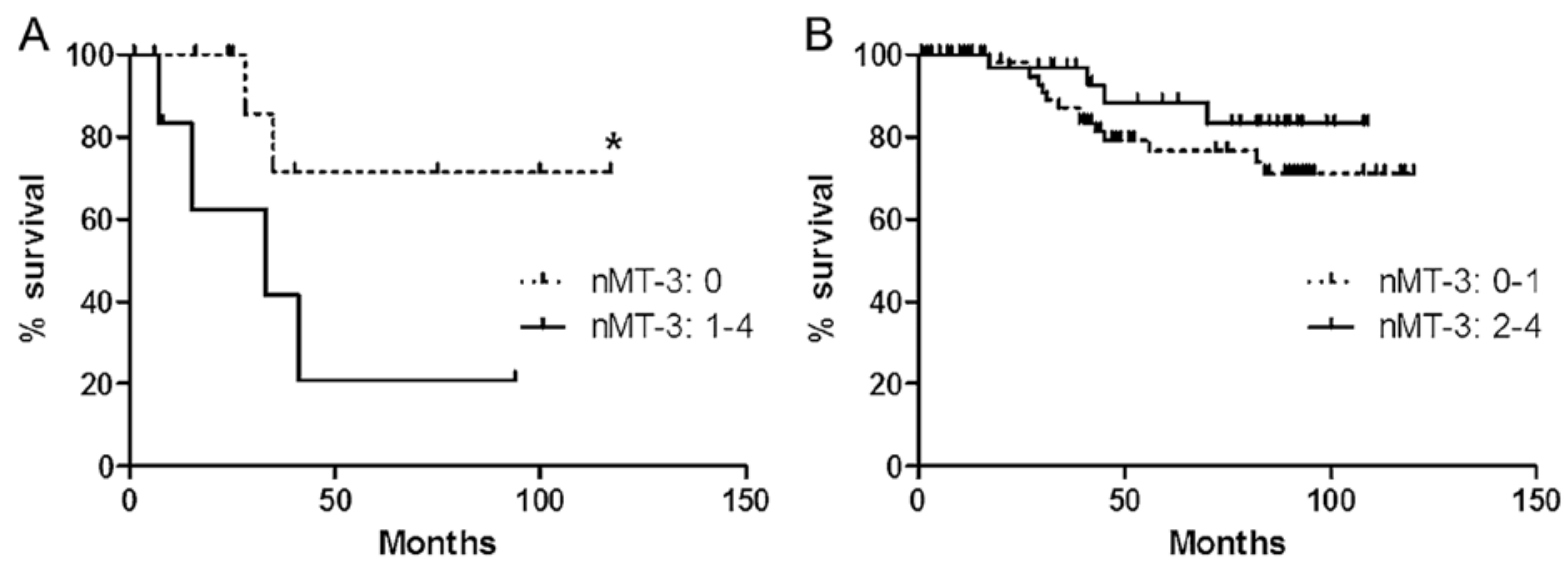

Figure 8. Kaplan-Meier overall survival curves in regard to nuclear metallothionein 3 (nMT-3) expression in triple-negative (TNBC) (A) and non-triplenegative (other group) (B) breast cancer cases. Analysis using Mantel-Cox test. "p $<0.05$.

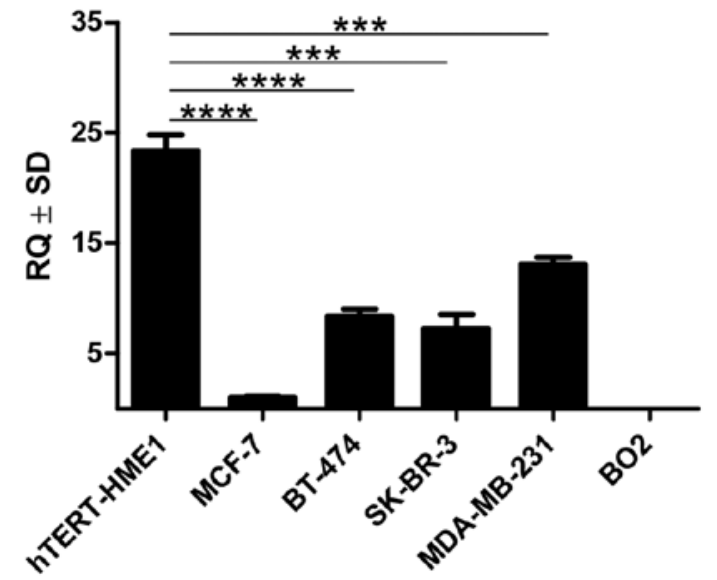

Figure 9. Metallothionein 3 (MT-3) mRNA expression in MCF-7, BT-474, SK-BR-3, MDA-MB-231 and BO2 breast cancer cell lines and in hTERT-HME1 normal human breast epithelial cell line. Analysis using unpaired t-test. **** $\mathrm{p}<0.001 ;{ }^{* * * *} \mathrm{p}<0.0001$. cases with nMT-3 expression manifested a significantly shorter overall survival ( $<<0.05$; Fig. 8).

In the real-time PCR patient cohort, none of the analyzed parameters, including MT-3 mRNA expression level, had any impact on the patient OS (Table II).

MT-3 mRNA expression level in the examined cell lines. The level of MT-3 mRNA in the MCF-7, BT-474, SK-BR-3 and MDA-MB-231 breast cancer cell lines was markedly lower than in the hTERT-HME1 line of normal human breast epithelial cells $(\mathrm{p}<0.001)$. The BO2 cell line showed no expression of MT-3 (Fig. 9).

\section{Discussion}

MT-3 was discovered in the central nervous system as a growth inhibitory factor (GIF) $(6,29)$. In vitro studies have shown that 
its presence inhibits the growth of nerve cells and neurite formation $(6,30,33)$. A similar effect has been observed in glial cells (49). There is also evidence that MT-3 protects cells against the harmful effects of free radicals, prevents DNA damage, and participates in repair processes (50-54). The role of MT-3 outside the central nervous system has not yet been clarified. Also unknown is the cause of the changes that are seen in the expression of this protein in tumors.

The increased expression of MT-3 was originally described in cancers of the prostate and the bladder. It was found that the level of this protein correlates with the tumor malignancy grade $(36,39)$. The results in bladder cancer appear particularly promising: they suggest that MT-3 may be an effective biomarker in this type of tumor (39). The increased expression of MT-3 has also been observed in breast cancers, but its prognostic value cannot be clearly described on the basis of these results. Sens et al initially observed that increased expression of MT-3 is associated with poor prognosis (40). Although no significant relationship was found between the expression of MT-3 and the clinicopathological factors they investigated, the level of MT-3 protein was significantly higher in cases characterized by an unfavorable course of the disease. The difference was even more pronounced in the preinvasive ductal breast cancer DCIS (40). Later, the same group of researchers published the results of a study on MT-3 expression in breast cancer carried out on a larger group of cases. It was observed that the lack of MT-3 expression is a rare but favorable prognostic factor. However, the previous results were not confirmed, and no association was found between the level of MT-3 and the prognosis (55).

Our studies were carried out on a homogeneous and well-characterized group of invasive ductal breast cancers (IDC). To compare the level of expression of the MT-3 protein in cancerous and non-cancerous tissue, we used cases of mastopathy. The presence of the MT-3 protein was demonstrated by immunohistochemistry in breast cancer cells as well as in normal mammary gland cells within the mastopathies. The MT-3 expression, on both the protein and mRNA levels, was significantly lower in cases of breast cancer than in nonmalignant tissue. This result differs fundamentally from those of previous publications, which showed a lack of MT-3 expression in normal breast tissue. As a consequence, changes in the expression of MT-3 in cases of breast cancer were interpreted as overexpression $(40,55)$.

Furthermore, in our study we observed that expression of MT-3 in cancer cells and normal breast cells occurs in both the cytoplasm and the cell nuclei. For this reason, the evaluation of the immunohistochemical reaction was carried out separately in each cellular compartment. The importance of subcellular localization of MTs has already been seen in the case of MT-1 and MT-2. The translocation of these proteins from the cytoplasm to the nucleus was observed, for instance, in the region of hyperplasia in certain cancers as well as in vitro in cells that were either proliferating or treated with high concentrations of glucose and cytostatics (56-59). It also seems that the separate assessment of the cytoplasmic and nuclear fractions of MT-1 and MT-2 within the tumor cells may have prognostic and predictive significance $(26,60,61)$. This has been confirmed by recent studies of MT-3 expression in non-small cell lung cancers. It was shown that the nuclear expression of MT-3 was significantly lower in cases of lung cancer than in normal tissue, and decreased with the increasing malignancy of cancer. In turn, the cytoplasmic expression of MT-3 in cases of lung cancer was higher than in normal tissue. It was also found that a lower cytoplasmic expression of MT-3 correlated positively with the size of the primary tumor and is associated with a poor prognosis (43). In our study, we have shown that both the nuclear and cytoplasmic expression of the MT-3 protein in cases of breast cancer is significantly lower than in cases of non-cancerous tissue. However, we observed no significant correlation between the level of MT-3 protein and the clinicopathological factors and prognosis. The difference in the expression of MT-3 in breast cancer cells and in non-cancerous tissue suggests that MT-3 may play the role of suppressor of the malignant transformation of breast epithelial cells.

It is also worth noting that we examined expression of the MT-3 protein in triple-negative and non-triple-negative breast cancer cases. It is well known that breast cancers of the triplenegative phenotype, which do not express ER, PR and HER2, are characterized by a more aggressive course, poor response to standard treatment and significantly worse prognosis $(62,63)$. We have found that nuclear expression of MT-3 is significantly lower in triple-negative breast cancer cases as compared to the other studied breast cancer samples. Interestingly, in our study nuclear expression of MT-3 in triple-negative breast cancers was associated with significantly shorter overall survival of patients. A similar result was obtained by Kmiecik et al, however this phenomenon is now difficult to explain, and requires further studies (64).

Our results are consistent with other authors who showed that expression of MT-3 is decreased in gastric carcinoma, esophageal squamous cell carcinoma, and adenocarcinoma of the esophagus $(41,42,65,66)$. As in our study, it has not been shown that the reduced expression of MT-3 has any relationship with clinicopathological factors or survival. It has been found that underlying this phenomenon are epigenetic processes such as DNA methylation within intron 1 and the promoter of the MT-3 gene, as well as modifications of histones $(42,65,66)$. Although the mechanism by which the expression of the MT-3 gene is silenced in tumors of the gastrointestinal tract has been determined by in vitro studies, the causes of this phenomenon are unknown. Initially the relationship between the degree of methylation of the MT-3 gene and prognostic factors was unknown $(42,65)$. However, detailed analysis of the profile of epigenetic changes in cancers of the esophagus showed that methylation of only a specific region within the promoter of the MT-3 gene is responsible for the inhibition of transcription and strongly correlates with the progression of cancer and metastases in the lymph nodes (66). A decrease of MT-3 expression has also been observed in bone marrow cells in the course of acute lymphoblastic leukemia in children (67). As with the gastrointestinal tract tumors, the inhibition of MT-3 synthesis was the result of hypermethylation in the promoter of MT-3 gene.

The reduced expression of MT-3, seen in the cells of some cancers, could suggest the suppressive role of the protein, analogously to its function in the nervous system. In vitro studies using stable transfection have demonstrated that MT-3 can inhibit the growth not only of neurons, but also cells of 
epithelial origin, such as PC-3 prostate cancer cells or MCF-7 and Hs578T breast cancer cells $(68,69)$. However, the growth inhibitory activity of MT-3 was not confirmed in all breast cancer cell lines, since the overexpression of this protein had no effect on the growth of T-47D, MDA-MB-231, and BO2 cells $(64,69)$. The inhibition of cell proliferation associated with the overexpression of MT-3 has also been found in the Eca-109 and TE13 esophageal cancer cells as well as in the HL-60 and MV4-11 leukemia cells $(67,70)$. It is possible, that the decrease of MT-3 expression, associated with malignant transformation, results in the loss of certain suppressor mechanisms by cancer cells. This may aid cell proliferation, promote tumor development and facilitate metastases. Confirmation of this hypothesis may come from the results of the gene expression profile in primary tumors and metastases. Studies have shown that downregulation of MT-3 is one of the seventeen changes in gene expression characteristic of metastases and clearly correlates with a poor clinical outcome (71). A decrease of MT-3 expression was also observed in metastases of pituitary gland adenocarcinoma to the spinal cord (72). In the present study we have shown that in cases of breast cancer with metastases to lymph nodes, the MT-3 mRNA level was significantly lower than in cases without lymph node involvement.

The results obtained in the in vitro model also confirm our findings in the clinical specimens. We observed that the level of MT-3 mRNA in the MCF-7, BT-474, SK-BR-3, and MDA-MB-231 breast cancer cell lines were significantly lower than in the hTERT-HME1 line of normal human breast epithelial cells. Interestingly, the $\mathrm{BO} 2$ cell line, which is a metastasis of MDA-MB-231 cells to the bone, showed no expression of MT-3.

In conclusion, we have shown that the expression of MT-3 in cases of ductal breast cancer is decreased, compared to nonmalignant breast tissue. The results of this study suggest that MT-3 may play a role in the pathogenesis and progression of breast cancer.

\section{Acknowledgements}

This study was supported by research funds from the Ministry of Science and Higher Education, research project no. N N401 005437. Bartosz Pula was supported by the 'START' stipend awarded by the Foundation for Polish Science.

\section{References}

1. Coyle P, Philcox JC, Carey LC and Rofe AM: Metallothionein: the multipurpose protein. Cell Mol Life Sci 59: 627-647, 2002.

2. Romero-Isart $\mathrm{N}$ and Vasák M: Advances in the structure and chemistry of metallothioneins. J Inorg Biochem 88: 388-396, 2002.

3. Dziegiel P, Pula B, Kobierzycki C, Stasiolek M and PodhorskaOkolow M: Metallothioneins: structure and functions. Adv Anat Embryol Cell Biol 218: 3-20, 2016.

4. Vasák M: Advances in metallothionein structure and functions. J Trace Elem Med Biol 19: 13-17, 2005.

5. Thirumoorthy N, Manisenthil Kumar KT, Shyam Sundar A, Panayappan L and Chatterjee M: Metallothionein: an overview. World J Gastroenterol 13: 993-996, 2007.

6. Uchida Y, Takio K, Titani K, Ihara Y and Tomonaga M: The growth inhibitory factor that is deficient in the Alzheimer's disease brain is a 68 amino acid metallothionein-like protein. Neuron 7: 337-347, 1991.
7. Quaife CJ, Findley SD, Erickson JC, Froelick GJ, Kelly EJ, Zambrowicz BP and Palmiter RD: Induction of a new metallothionein isoform (MT-IV) occurs during differentiation of stratified squamous epithelia. Biochemistry 33: 7250-7259, 1994.

8. Moffatt P and Séguin C: Expression of the gene encoding metallothionein-3 in organs of the reproductive system. DNA Cell Biol 17: 501-510, 1998.

9. Haq F, Mahoney M and Koropatnick J: Signaling events for metallothionein induction. Mutat Res 533: 211-226, 2003.

10. Hozumi I, Suzuki JS, Kanazawa H, Hara A, Saio M, Inuzuka T, Miyairi S, Naganuma A and Tohyama C: Metallothionein-3 is expressed in the brain and various peripheral organs of the rat. Neurosci Lett 438: 54-58, 2008.

11. Sato M and Kondoh M: Recent studies on metallothionein: protection against toxicity of heavy metals and oxygen free radicals. Tohoku J Exp Med 196: 9-22, 2002.

12. Theocharis SE, Margeli AP and Koutselinis A: Metallothionein: a multifunctional protein from toxicity to cancer. Int $\mathbf{J}$ Biol Markers 18: 162-169, 2003.

13. Cherian MG, Jayasurya A and Bay BH: Metallothioneins in human tumors and potential roles in carcinogenesis. Mutat Res 533: 201-209, 2003.

14. Nielsen AE, Bohr A and Penkowa M: The Balance between life and death of cells: roles of metallothioneins. Biomark Insights 7: 99-111, 2007.

15. Theocharis SE, Margeli AP, Klijanienko JT and Kouraklis GP: Metallothionein expression in human neoplasia. Histopathology 45: 103-118, 2004.

16. Pedersen MØ, Larsen A, Stoltenberg M and Penkowa M: The role of metallothionein in oncogenesis and cancer prognosis. Prog Histochem Cytochem 44: 29-64, 2009.

17. Dziegiel P, Forgacz J, Suder E, Surowiak P, Kornafel J and Zabel M: Prognostic significance of metallothionein expression in correlation with $\mathrm{Ki}-67$ expression in adenocarcinomas of large intestine. Histol Histopathol 18: 401-407, 2003.

18. Tai SK, Tan OJ, Chow VT, Jin R, Jones JL, Tan PH, Jayasurya A and Bay BH: Differential expression of metallothionein 1 and 2 isoforms in breast cancer lines with different invasive potential: identification of a novel nonsilent metallothionein-1 $\mathrm{H}$ mutant variant. Am J Pathol 163: 2009-2019, 2003.

19. Dziegiel P, Salwa-Zurawska W, Zurawski J, Wojnar A and Zabel M: Prognostic significance of augmented metallothionein (MT) expression correlated with Ki-67 antigen expression in selected soft tissue sarcomas. Histol Histopathol 20: 83-89, 2005.

20. Gallicchio LM, Flaws JA, Fowler BA and Ioffe OB: Metallothionein expression in invasive and in situ breast carcinomas. Cancer Detect Prev 29: 332-337, 2005.

21. Szajerka A, Dziegiel P, Szajerka T, Zabel M, Winowski J and Grzebieniak Z: Immunohistochemical evaluation of metallothionein, MCM-2 and Ki-67 antigen expression in tumors of the adrenal cortex. Anticancer Res 28: 2959-2965, 2008.

22. Cardoso SV, Silveira-Júnior JB, De Carvalho Machado V, De-Paula AM, Loyola AM and De Aguiar MC: Expression of metallothionein and p53 antigens are correlated in oral squamous cell carcinoma. Anticancer Res 29: 1189-1193, 2009.

23. Wojnar A, Pula B, Piotrowska A, Jethon A, Kujawa K, Kobierzycki C, Rys J, Podhorska-Okolow M and Dziegiel P: Correlation of intensity of MT-I/II expression with Ki-67 and MCM-2 proteins in invasive ductal breast carcinoma. Anticancer Res 31: 3027-3033, 2011.

24. Wang N, Dong CR, Jiang R, Tang C, Yang L, Jiang QF, Chen GG and Liu ZM: Overexpression of HIF-1 $\alpha$, metallothionein and SLUG is associated with high TNM stage and lymph node metastasis in papillary thyroid carcinoma. Int J Clin Exp Pathol 15: 322-330, 2013.

25. Surowiak P, Matkowski R, Materna V, Györffy B, Wojnar A, Pudelko M, Dziegiel P, Kornafel J and Zabel M: Elevated metallothionein (MT) expression in invasive ductal breast cancers predicts tamoxifen resistance. Histol Histopathol 20: 1037-1044, 2005.

26. Surowiak P, Materna V, Maciejczyk A, Pudełko M, Markwitz E, Spaczyński M, Dietel M, Zabel M and Lage H: Nuclear metallothionein expression correlates with cisplatin resistance of ovarian cancer cells and poor clinical outcome. Virchows Arch 450: 279-285, 2007.

27. Yap X, Tan HY, Huang J, Lai Y, Yip GW, Tan PH and Bay BH: Over-expression of metallothionein predicts chemoresistance in breast cancer. J Pathol 217: 563-570, 2009. 
28. Dziegiel P, Pula B, Kobierzycki C, Stasiolek M and PodhorskaOkolow M: The role of metallothioneins in carcinogenesis. Adv Anat Embryol Cell Biol 218: 29-63, 2016.

29. Palmiter RD, Findley SD, Whitmore TE and Durnam DM MT-III, a brain-specific member of the metallothionein gene family. Proc Natl Acad Sci USA 89: 6333-6337, 1992.

30. Tsuji S, Kobayashi H, Uchida Y, Ihara Y and Miyataka T: Molecular cloning of human growth inhibitory factor cDNA and its downregulationin Alzheimer's disease. EMBO J 11: $48434850,1992$.

31. Sogawa CA, Asanuma M, Sogawa N, Miyazaki I, Nakanishi T, Furuta $\mathrm{H}$ and Ogawa N: Localization, regulation, and function of metallothionein-III/growth inhibitory factor in the brain. Acta Med Okayama 55: 1-9, 2001.

32. Dziegiel P, Pula B, Kobierzycki C, Stasiolek M and PodhorskaOkolow M: Metallothionein-3. Adv Anat Embryol Cell Biol 218: 21-27, 2016.

33. Sewell AK, Jensen LT, Erickson JC, Palmiter RD and Winge DR Bioactivity of metallothionein-3 correlates with its novel beta domain sequence rather than metal binding properties. Biochemistry 34: 4740-4747, 1995.

34. Hoey JG, Garrett SH, Sens MA, Todd JH and Sens DA: Expression of MT-3 mRNA in human kidney, proximal tubule cell cultures, and renal cell carcinoma. Toxicol Lett 92: 149-160, 1997.

35. Garrett SH, Sens MA, Todd JH, Somji S and Sens DA: Expression of MT-3 protein in the human kidney. Toxicol Lett 105: 207-214, 1999.

36. Garrett SH, Sens MA, Shukla D, Nestor S, Somji S, Todd JH and Sens DA: Metallothionein isoform 3 expression in the human prostate and cancer-derived cell lines. Prostate 41: 196-202, 1999.

37. Kim D, Garrett SH, Sens MA, Somji S and Sens DA: Metallothionein isoform 3 and proximal tubule vectorial active transport. Kidney Int 61: 464-472, 2002.

38. Irie Y, Mori F, Keung WM, Mizushima Y and Wakabayashi K: Expression of neuronal growth inhibitory factor (metallothionein-III) in the salivary gland. Physiol Res 53: 719-723, 2004.

39. Sens MA, Somji S, Lamm DL, Garrett SH, Slovinsky F, Todd JH and Sens DA: Metallothionein isoform 3 as a potential biomarker for human bladder cancer. Environ Health Perspect 108: 413-418, 2000.

40. Sens MA, Somji S, Garrett SH, Beall CL and Sens DA Metallothionein isoform 3 overexpression is associated with breast cancers having a poor prognosis. Am J Pathol 159: 21-26, 2001.

41. El-Rifai W, Frierson HF Jr, Harper JC, Powell SM and Knuutila S: Expression profiling of gastric adenocarcinoma using cDNA array. Int J Cancer 92: 832-838, 2001.

42. Smith E, Drew PA, Tian ZQ, De Young NJ, Liu JF, Mayne GC, Ruszkiewicz AR, Watson DI and Jamieson GG: Metallothionien 3 expression is frequently down-regulated in oesophageal squamous cell carcinoma by DNA methylation. Mol Cancer 13 : $42,2005$.

43. Werynska B,Pula B,Muszczynska-Bernhard B, Gomulkiewicz A, Jethon A, Podhorska-Okolow M, Jankowska R and Dziegiel P: Expression of metallothionein-III in patients with non-small cell lung cancer. Anticancer Res 33: 965-974, 2013.

44. Ellis IO, Schnitt SJ, Sastre-Garau X, Bussolati G, Tavassoli FA, Eusebi V, Peterse JL, Mukai K, Tabár L, Jacquemier J, et al: Invasive breast carcinoma. In: Pathology and Genetics of Tumours of the Breast and Female Genital Organs. World Health Organization Classification of Tumours. Tavassoli FA and Devilee P (eds). IARC Press, Lyon, pp13-59, 2003.

45. Remmele W and Stegner HE: Recommendation for uniform definition of an immunoreactive score (IRS) for immunohistochemical estrogen receptor detection (ER-ICA) in breast cancer. Pathologe 8: 138-140, 1987 (In German).

46. Gomulkiewicz A, Podhorska-Okolow M, Szulc R, Smorag Z, Wojnar A, Zabel M and Dziegiel P: Correlation between metallothionein (MT) expression and selected prognostic factors in ductal breast cancers. Folia Histochem Cytobiol 48: 242-248, 2010.

47. Mueller-Holzner E, Fink V, Frede T and Marth C: Immunohistochemical determination of HER2 expression in breast cancer from core biopsy specimens: a reliable predictor of HER2 status of the whole tumor. Breast Cancer Res Treat 69: 13-19, 2001.
48. Livak KJ and Schmittgen TD: Analysis of relative gene expression data using real-time quantitative PCR and the $2^{-\Delta \Delta C}$ method. Methods 25: 402-408, 2001.

49. Amoureux MC, Wurch T and Pauwels PJ: Modulation of metallothionein-III mRNA content and growth rate of rat C6-glial cells by transfection with human 5-HT1D receptor genes. Biochem Biophys Res Commun 214: 639-645, 1995.

50. You HJ, Oh DH, Choi CY, Lee DG, Hahm KS, Moon AR and Jeong HG: Protective effect of metallothionein-III on DNA damage in response to reactive oxygen species. Biochim Biophys Acta 1573: 33-38, 2002

51. Jeong HG, Youn CK, Cho HJ, Kim SH, Kim MH, Kim HB, Chang IY, Lee YS, Chung MH and You HJ: Metallothionein-III prevents gamma-ray-induced 8-oxoguanine accumulation in normal and hOGG1-depleted cells. J Biol Chem 279: 34138-34149, 2004.

52. Hozumi I, Uchida Y, Watabe K, Sakamoto T and Inuzuka T: Growth inhibitory factor (GIF) can protect from brain damage due to stab wounds in rat brain. Neurosci Lett 395: 220-223, 2006.

53. Kim HG, Hwang YP and Jeong HG: Metallothionein-III induces HIF-1 alpha-mediated VEGF expression in brain endothelial cells. Biochem Biophys Res Commun 369: 666-671, 2008.

54. Luo Y, Xu Y, Bao Q, Ding Z, Zhu C, Huang ZX and Tan X: The molecular mechanism for human metallothionein-3 to protect against the neuronal cytotoxicity of $\mathrm{A} \beta(1-42)$ with $\mathrm{Cu}$ ions. J Biol Inorg Chem 18: 39-47, 2013.

55. Somji S, Garrett SH, Zhou XD, Zheng Y, Sens DA and Sens MA: Absence of metallothionein 3 expression in breast cancer is a rare, but favorable marker of outcome that is under epigenetic control. Toxicol Environ Chem 92: 1673-1695, 2010.

56. Cherian MG and Apostolova MD: Nuclear localization of metallothionein during cell proliferation and differentiation. Cell Mol Biol (Noisy-le-grand) 46: 347-356, 2000.

57. Apostolova MD, Chen S, Chakrabarti S and Cherian MG: Highglucose-induced metallothionein expression in endothelial cells: an endothelin-mediated mechanism. Am J Physiol Cell Physiol 281: C899-C907, 2001.

58. Bay BH, Jin R and Jayasurya A: Analysis of metallothionein expression in human cancers. Acta Histochem Cytochem 34: 171-176, 2001.

59. Takahashi Y, Ogra Y and Suzuki KT: Nuclear trafficking of metallothionein requires oxidation of a cytosolic partner. J Cell Physiol 202: 563-569, 2005.

60. Szelachowska J, Dziegiel P, Jelen-Krzeszewska J, Jelen M, Tarkowski R, Wlodarska I, Spytkowska B, Gisterek I, Matkowski R and Kornafel J: Prognostic significance of nuclear and cytoplasmic expression of metallothioneins as related to proliferative activity in squamous cell carcinomas of oral cavity. Histol Histopathol 23: 843-851, 2008.

61. Kobierzycki C, Pula B, Skiba M, Jablonska K, Latkowski K, Zabel M, Nowak-Markwitz E, Spaczynski M, Kedzia W, Podhorska-Okolow M, et al: Comparison of minichromosome maintenance proteins (MCM-3, MCM-7) and metallothioneins (MT-I/II, MT-III) expression in relation to clinicopathological data in ovarian cancer. Anticancer Res 33: 5375-5383, 2013.

62. Elias AD: Triple-negative breast cancer: a short review. Am J Clin Oncol 33: 637-645, 2010.

63. Lin NU, Vanderplas A, Hughes ME, Theriault RL, Edge SB, Wong YN, Blayney DW, Niland JC, Winer EP and Weeks JC: Clinicopathologic features, patterns of recurrence, and survival among women with triple-negative breast cancer in the National Comprehensive Cancer Network. Cancer 118: 5463-5472, 2012.

64. Kmiecik AM, Pula B, Suchanski J, Olbromski M, Gomulkiewicz A, Owczarek T, Kruczak A, Ambicka A, Rys J, Ugorski, et al: Metallothionein-3 increases triple-negative breast cancer cell invasiveness via induction of metalloproteinase expression. PLoS One 10: e0124865, 2015.

65. Deng D, El-Rifai W, Ji J, Zhu B, Trampont P, Li J, Smith MF and Powel SM: Hypermethylation of metallothionein-3 CpG island in gastric carcinoma. Carcinogenesis 24: 25-29, 2003.

66. Peng D, Hu TL, Jiang A, Washington MK, Moskaluk CA, Schneider-Stock R and El-Rifai W: Location-specific epigenetic regulation of the metallothionein 3 gene in esophageal adenocarcinomas. PLoS One 6: e22009, 2011.

67. Tao YF, Xu LX, Lu J, Cao L, Li ZH, Hu SY, Wang NN, Du XJ, Sun LC, Zhao WL, et al: Metallothionein III (MT3) is a putative tumor suppressor gene that is frequently inactivated in pediatric acute myeloid leukemia by promoter hypermethylation. J Transl Med 12: 182, 2014. 
68. Dutta R, Sens DA, Somji S, Sens MA and Garrett SH: Metallothionein isoform 3 expression inhibits cell growth and increases drug resistance of PC-3 prostate cancer cells. Prostate 52: 89-97, 2002.

69. Gurel V, Sens DA, Somji S, Garrett SH, Nath J and Sens MA: Stable transfection and overexpression of metallothionein isoform 3 inhibits the growth of MCF-7 and Hs578T cells but not that of T-47D or MDA-MB-231 cells. Breast Cancer Res Treat 80: 181-191, 2003

70. Tian ZQ, Xu YZ, Zhang YF, Ma GF, He M and Wang GY: Effects of metallothionein-3 and metallothionein-1E gene transfection on proliferation, cell cycle, and apoptosis of esophageal cancer cells. Genet Mol Res 12: 4595-4603, 2013.
71. Ramaswamy S, Ross KN, Lander ES and Golub TR: A molecular signature of metastasis in primary solid tumors. Nat Genet 33: 49-54, 2003.

72. Giorgi RR, Correa-Giannella ML, Casarini AP, Machado MC, Bronstein MD, Cescato VA and Giannella-NetoD: Metallothionein isoform 3 gene is differentially expressed in corticotropinproducing pituitary adenomas. Neuroendocrinology 82: 208-214, 2005. 